\title{
Kırgızistan Dış Ticaret Dengesinin Belirleyicileri
}

Jusup PIRIMBAEV, Department of Economics, Faculty of Economics and Administrative Sciences, KyrgyzstanTurkey Manas University, Kyrgyzstan; e-mail: jusup@netmail.kg

Zamira OSKONBAEVA, Department of Economics, Faculty of Economics and Administrative Sciences, Kyrgyzstan-Turkey Manas University, Kyrgyzstan; e-mail: zama2008.82@mail.ru

\section{Determinants of Kyrgyzstan's Trade Balance ${ }^{2}$}

\begin{abstract}
This study aims to estimate using monthly data for the 2000-2013 period, the main determinants of the trade balance of Kyrgyzstan. For this purpose, in the framework of the Autoregressive Distributed Lag (ARDL) model were used the following variables: the balance of trade (export/import), GDP, the real exchange rate and money supply (M2). The results of the econometric analysis show that the monetary and the elasticity models perform better. In other words, $1 \%$ increase in the real exchange rate leads to an improvement in the trade balance by about $1.09 \%$, and $1 \%$ decrease in the money supply leads to an improvement in the trade balance by about $0.51 \%$. In the long run Marshall-Lerner condition is observed while in the short term is not found $\mathrm{J}$-curve effect.
\end{abstract}

Keywords

Foreign Trade Balance, ARDL Model, Elasticity Approach, Absorption Approach, Monetarist Approach, J-curve.

JEL Classification Codes $\quad: \quad F 1$, F14.

\section{$\ddot{O} \mathbf{z}$}

Bu çalışma Kırgızistan dış ticaretinin temel belirleyicilerini 2000-2013 dönemine ait aylık verileri kullanarak tahmin etmeyi amaçlamaktadır. Bu amaç için yurtiçi gelir, reel döviz kuru ve para arzı değişkenlerine sınır testi yaklaşımına dayanan ARDL modeli uygulanmıştır. Elastikiyet, massetme ve parasalcı yaklaşımlar karşılaştırılarak, parasalcı ve elastikiyet yaklaşımlarını destekleyen bulgulara ulaşılmıştır. Para arzındaki (LM2) $\% 1$ 'lik düşüş ticaret dengesini $\% 0,51$ oranında, reel döviz kurundaki (LREER) $\% 1$ 'lik artış ise ticaret dengesini $\% 1,09$ oranında iyileştireceği görülmüştür. Uzun dönemde Marshall-Lerner koşulunun geçerliliğine, kısa dönemde ise J-eğrisi hipotezinin geçerli olmadığına dair sonuçlar elde edilmiştir.

Anahtar Sözcükler : Diş Ticaret Dengesi, ARDL Modeli, Elastikiyet, Massetme, Parasalcı Yaklaşım, J-eğrisi.

I Bu makale Kirgızistan-Türkiye Manas Üniversitesi, Sosyal Bilimler Enstitüsü, İktisat Ana Bilim Dalında Prof.Dr. Cusup PIRIMBAYEV Danışmanlığında tamamlanan ve 2014 yllında jüri önünde savunulan “Kırgızistan Dış Ticaretinin Yapısal Analizi: (1991-2013)” başlıklı Doktora tezinden üretilmiştir.

2 This paper is generated from the part of the PhD thesis titled as "Structural Analysis of Kyrgyzstan's External Trade: 1991-2013" which was supervised by Prof. Dr. Jusup Pirmbaev, in Kyrgyzstan-Turkey Manas University, 2014. 


\section{Giriş}

1991'de Sovyetler Birliğinin dağılmasıyla bağımsızlığına kavuşan Kırgızistan dış ülkelere açılmaya başlamıştır. 23 yıl içinde ticaret dengesi ancak 2001 yılında fazla vermiştir. Yani ülke ekonomisi kronik dış ticaret açığı problemiyle karşı karşıya kalmıştır.

Çalışmamızın amacı Kırgızistan için dış ticaret dengesinin belirleyicilerini üç teorik yaklaşıma göre incelemektir. Bunlar elastikiyet, massetme ve parasalcı yaklaşım olarak bilinmektedir. Bu amaç için ARDL modeline dayanan sınır testi ve etki-tepki fonksiyonu kullanılmıştır. Çalışmanın bundan sonraki bölümünde teorik yaklaşımlarla ilgili bilgiler özetlenmiştir. Üçüncü bölüm diş ticaret dengesini araştıran ampirik çalışmaların yer aldığı literatürün incelendiği bölümdür. Dördüncü ve beşinci bölümde sirasıyla yöntem ve veriler hakkında açıklamalar yapılmıştır. Altıncı bölümde ekonometrik tahmin sonucunda elde edilen bulgulara yer verilmiştir. Çalışma sonuç bölümü ile sona ermektedir.

\section{Teorik Çerçeve}

Ticaret dengesinin oluşmasında ilk yaklaşım elastikiyet yaklaşımıdır. Söz konusu yaklaşım Bickerdike (1920), Robinson (1947) ve Metzler (1948) tarafindan geliştirilmiştir. Kısaca BRM modeli olarak literatürde yer almaktadır. Bu yaklaşım döviz kuru ile ticaret dengesi arasındaki ilişki üzerinde yoğunlaşmaktadır. Devalüasyon sonrası ticaret dengesinin iyileşmesi Marshall-Lerner koşulunun $\left(\left|E_{m}\right|+\left|E_{X}\right|>1\right)$ geçerli olup olmamasına bağlıdır. Ancak kısa dönemde bu koşulun sağlanamaması J-eğrisi etkisi ile açıklanabilmektedir. Jeğrisi, devalüasyonun ilk dönemlerde dış ticaret dengesini kötüleştireceğini, ancak bu durumun belirli bir süre sonra tersine döneceğini iddia eden etkidir (Magee, 1973).

Ticaret dengesini açıklamaya yönelik geliştirilen yaklaşımlardan bir diğeri Harberger (1950), Meade (1951) ve Alexander (1952, 1959) tarafindan ortaya atılan massetme yaklaşımıdır. Bu yaklaşıma göre ticaret dengesi yurtiçi gelir ile yurtiçi harcamalar arasındaki fark olarak ele alınmaktadır (Harberger 1950; Meade 1951 ve Alexander 1952, 1959). Yani ticaret dengesinin iyileşmesi yurtiçi gelirin yurtiçi harcamalardan büyük olması durumunda gerçekleşebildiğini öne sürmektedir.

Ticaret dengesiyle ilgili üçüncü yaklaşım Polak (1957) Mundell (1968) ve Johnson (1972) tarafından geliştirilen parasalcı yaklaşımdır. Diğer bir deyişle ödemeler bilançosunun parasal olgu olduğu öne sürülmektedir (Johnson 1977). Bu yaklaşıma göre ticaret dengesindeki dengesizlikler para arzı ve para talebiyle açıklanabilmektedir. Yani ülke içinde para talebi para arzını aşarsa bu talep yurtdışından giren para akımıyla karşılanacaktır. $\mathrm{Bu}$ durumda ticaret dengesi iyileşecektir. Diğer yandan para arzı para talebinden fazla ise, 
yurtdışına para akımıyla bu fazlalık ortadan kalkacaktır. Yani bu durumda ticaret dengesinin açık vereceği öne sürülmektedir (Duasa, 2007: 23).

Yurtiçi gelirin ticaret dengesi üzerindeki etkisi massetme ve parasalcı yaklaşımlarda iki farklı yöndedir. Massetme yaklaşımına göre yurtiçi gelirdeki artış ithalat miktarını artırmakta ve böylece ticaret dengesini olumsuz yönde etkilemektedir. Parasalcı yaklaşımda ise artan gelir işlem amaçlı para talebini artıracaktır. Eğer Merkez Bankası para arzını artırmazsa ülke içindeki likidite açı̆̆ı yabancı ülkelerden döviz girişi yoluyla karşılanacak, bu da ödemeler bilançosunun fazla vermesine yol açacaktır.

\section{Literatür}

Hem gelişmiş hem de gelişmekte olan ülkelerin diş ticaret dengesini açıklamaya yönelik farklı dönemlerde ve çeşitli yöntemlerle pek fazla ampirik çalışmalar yapılmıştır. Bunlardan bazıları Tablo: 1'de özetlenmiştir:

Tablo: 1

\section{Literatür}

\begin{tabular}{|c|c|c|c|c|}
\hline Yazarlar & Ülke & Değişkenler & Yöntem & Sonuç \\
\hline Ono vd. (2014) & Japonya & $\begin{array}{l}\text { Ticaret haddi, net } \\
\text { ihracat/GSYİH, reel döviz } \\
\text { kuru }\end{array}$ & VAR modeli & J-eğrisi etkisi var. \\
\hline Ray (2012) & Hindistan & $\begin{array}{l}\text { Reel döviz kuru, yurtiçi } \\
\text { tüketim, yurtdışı gelir, } \\
\text { doğrudan yabancı } \\
\text { yatırımlar }\end{array}$ & $\begin{array}{l}\text { Johansen } \\
\text { eşbütünleşme, VECM }\end{array}$ & $\begin{array}{l}\text { Yurtdışı gelir ile ticaret dengesi } \\
\text { arasında pozitif yönde ilişki } \\
\text { bulunmuştur. Yurtiçi tüketim ile döviz } \\
\text { kurunun ticaret dengesine etkisi negatif } \\
\text { yöndedir. }\end{array}$ \\
\hline $\begin{array}{l}\text { İrhan vd. } \\
\text { (2011) }\end{array}$ & Türkiye & $\begin{array}{l}\text { Reel döviz kuru, yurtiçi, } \\
\text { yurtdış1 gelir ve ham } \\
\text { petrol fiyatları }\end{array}$ & ARDL & $\begin{array}{l}\text { Döviz kurunun değer kaybetmesi } \\
\text { ticaret dengesini olumlu etkiler. Yurtiçi } \\
\text { gelir ters yönde, yurtdışı gelir pozitif } \\
\text { yönde etkiler. }\end{array}$ \\
\hline $\begin{array}{l}\text { Sun ve Chiu } \\
\text { (2010) }\end{array}$ & Tayvan & $\begin{array}{l}\text { Ticaret dengesi ve döviz } \\
\text { kuru }\end{array}$ & ARDL & $\begin{array}{l}\text { Tayvan ile ABD arasındaki ticarette J- } \\
\text { eğrisi etkisi var. Tayvan ile Japonya } \\
\text { arasındaki ticarette döviz kuru ve } \\
\text { ticaret dengesi arasında uzun dönem } \\
\text { ilişki bulunmamıştır. }\end{array}$ \\
\hline $\begin{array}{l}\text { Muhammad } \\
(2010)\end{array}$ & Pakistan & $\begin{array}{l}\text { Reel döviz kuru, yurtiçi } \\
\text { tüketim, yurtdışı gelir, } \\
\text { doğrudan yabancı } \\
\text { yatırımlar } \\
\end{array}$ & $\begin{array}{l}\text { Johansen } \\
\text { eşbütünleşme, VECM }\end{array}$ & $\begin{array}{l}\text { Yurtiçi tüketimin ticaret dengesine } \\
\text { etkisi negatif yöndedir. Yabancı } \\
\text { yatırımlar ve reel döviz kurunun ticaret } \\
\text { dengesine etkisi olumludur. }\end{array}$ \\
\hline Kim (2009) & Kore & $\begin{array}{l}\text { Reel döviz kuru, yurtiçi } \\
\text { yurtdışı gelir ve göreli } \\
\text { para arzı }\end{array}$ & $\begin{array}{l}\text { Johansen } \\
\text { eşbütünleşme, hata } \\
\text { düzeltme modeli }\end{array}$ & ML koşulu geçerli, J- eğrisi etkisi var. \\
\hline $\begin{array}{l}\text { Matesanz ve } \\
\text { Fugarolas } \\
\text { (2009) }\end{array}$ & Arjantin & $\begin{array}{l}\text { Reel döviz kuru, yurtiçi ve } \\
\text { yurtdışı gelir }\end{array}$ & $\begin{array}{l}\text { Johansen } \\
\text { eşbütünleşme, Var } \\
\text { modeli }\end{array}$ & $\begin{array}{l}\text { Sabit döviz kuru rejiminde ML koşulu } \\
\text { geçerli }\end{array}$ \\
\hline
\end{tabular}




\begin{tabular}{|c|c|c|c|c|}
\hline $\begin{array}{l}\text { Yuen-Ling vd. } \\
\text { (2008) }\end{array}$ & Malezya & $\begin{array}{l}\text { Reel döviz kuru, yurtiçi ve } \\
\text { yurtdışı gelir }\end{array}$ & $\begin{array}{l}\text { Eşbütünleşme, VAR } \\
\text { modeli, Granger } \\
\text { nedensellik }\end{array}$ & ML koşulu geçerli, J- eğrisi etkisi yok. \\
\hline $\begin{array}{l}\text { Hooy ve Chan } \\
(2008)\end{array}$ & \begin{tabular}{|l} 
Çin ve \\
Malezya
\end{tabular} & $\begin{array}{l}\text { Reel döviz kuru, yurtiçi ve } \\
\text { yurtdışı gelir }\end{array}$ & ARDL ve VAR modeli & ML koşulu geçerli, J- eğrisi etkisi yok. \\
\hline Duasa (2007) & Malezya & $\begin{array}{l}\text { Reel döviz kuru, yurtiçi } \\
\text { gelir ve parasal büyüklük } \\
\text { M2 }\end{array}$ & ARDL & $\begin{array}{l}\text { Parasalcı yaklaşımı doğrulayan } \\
\text { sonuçlara ulaşılmıştır. ML koşulu } \\
\text { geçerli değil. }\end{array}$ \\
\hline $\begin{array}{l}\text { Gomes ve Paz } \\
(2005)\end{array}$ & Brezilya & $\begin{array}{l}\text { Ticaret dengesi, döviz } \\
\text { kuru }\end{array}$ & VECM & Marshall-lerner koşulu geçerli \\
\hline $\begin{array}{l}\text { Narayan ve } \\
\text { Narayan. } \\
\text { (2004). }\end{array}$ & Fiji & $\begin{array}{l}\text { Reel döviz kuru, yurtiçi ve } \\
\text { yurtdışı gelir }\end{array}$ & $\begin{array}{l}\text { ARDL, FMOLS, VAR } \\
\text { modeli }\end{array}$ & $\mathrm{J}$-eğrisi etkisi var \\
\hline Narayan (2004) & Yeni Zelanda & $\begin{array}{l}\text { Reel döviz kuru, yurtiçi ve } \\
\text { yurtdıș1 gelir }\end{array}$ & $\begin{array}{l}\text { Granger nedensellik, } \\
\text { VAR modeli, }\end{array}$ & J-eğrisi etkisi var \\
\hline $\begin{array}{l}\text { Onafowora } \\
\text { (2003) }\end{array}$ & \begin{tabular}{|l|} 
Tayland, \\
Malezya, \\
Endonezya \\
\end{tabular} & $\begin{array}{l}\text { Reel döviz kuru, yurtiçi ve } \\
\text { yurtdış1 gelir }\end{array}$ & $\begin{array}{l}\text { Eşbütünleşme, hata } \\
\text { düzeltme modeli, }\end{array}$ & $\begin{array}{l}\text { J-eğrisi etkisi var. Marshall-Lerner } \\
\text { koşulu geçerlidir }\end{array}$ \\
\hline Singh (2002) & Hindistan & $\begin{array}{l}\text { Reel döviz kuru, yurtiçi ve } \\
\text { yurtdışı gelir }\end{array}$ & VAR modeli & $\begin{array}{l}\text { Reel döviz kuru ve yurtiçi gelirin } \\
\text { ticaret dengesi üzerinde anlamlı etkisi } \\
\text { bulunmuştur. }\end{array}$ \\
\hline $\begin{array}{l}\text { Lal ve } \\
\text { Lowinger } \\
(2002)\end{array}$ & $\begin{array}{l}5 \text { Güney Asya } \\
\text { ülkesi }\end{array}$ & $\begin{array}{l}\text { Reel döviz kuru, yurtiçi ve } \\
\text { yurtdışı gelir }\end{array}$ & $\begin{array}{l}\text { Johansen } \\
\text { eşbütünleşme, hata } \\
\text { düzeltme modeli, etki } \\
\text { tepki fonksiyonu }\end{array}$ & J-eğrisi etkisi var \\
\hline $\begin{array}{l}\text { Wilson ve Tat } \\
(2001)\end{array}$ & Singapur & $\begin{array}{l}\text { Ticaret dengesi, reel döviz } \\
\text { kuru, yurtiçi ve yurtdışı } \\
\text { gelir }\end{array}$ & Eşbütünleşme & J-eğrisi etkisi yok \\
\hline Weixian (1999) & Çin & $\begin{array}{l}\text { Ticaret dengesi, reel döviz } \\
\text { kuru, yurtiçi ve yurtdışı } \\
\text { gelir, yurtiçi ve yurtdışı } \\
\text { para arzı }\end{array}$ & Eşbütünleşme & $\begin{array}{l}\text { J-eğrisi etkisi var. Elastikiyet, parasalcı } \\
\text { ve massetme yaklaşımları } \\
\text { karşılaştırılarak Çin'de elastikiyet } \\
\text { yaklaşımının geçerli olduğu sonucuna } \\
\text { varılmıştır. }\end{array}$ \\
\hline $\begin{array}{l}\text { Bahmani- } \\
\text { Oskooee ve } \\
\text { Brooks (1999) }\end{array}$ & $\mathrm{ABD}$ & $\begin{array}{l}\text { Yurtiçi ve yurtdış1 gelir, } \\
\text { döviz kuru }\end{array}$ & ARDL & $\begin{array}{l}\text { J-eğrisi etkisi yok. Fakat uzun } \\
\text { dönemde döviz kuru ve ticaret dengesi } \\
\text { arasında anlamlı ilișki bulunmaktadır. }\end{array}$ \\
\hline Rincon (1998) & Kolombiya & $\begin{array}{l}\text { Ticaret dengesi, reel döviz } \\
\text { kuru, para arzı, yurtiçi } \\
\text { gelir }\end{array}$ & Eşbütünleşme & ML koşulu geçerli \\
\hline $\begin{array}{l}\text { Shirvani ve } \\
\text { Wilbratte } \\
\text { (1997) }\end{array}$ & $\mathrm{ABD}$ & $\begin{array}{l}\text { Ticaret dengesi, reel döviz } \\
\text { kuru }\end{array}$ & Eşbütünleşme & ML koşulu geçerli. \\
\hline
\end{tabular}

\section{Sinır Testi}

Ticaret dengesi, yurtiçi gelir, reel döviz kuru ve parasal büyüklük arasındaki uzun dönem ilişkiyi incelediğimiz bu çalışmada Pesaran vd. (2001) tarafından geliştirilen sınır testi yaklaşımı kullanılacaktır.

Sınır testi gecikmesi dağıtılmış otoregresif modele dayanmaktadır. $\mathrm{Bu}$ model yapısı genel olarak aşağıdaki şekilde gösterilebilir. 


$$
\Delta y_{t}=c_{0}+c_{1} t+\pi_{y y} y_{t-1}+\pi_{y x . x} x_{t-1}+\sum_{i=1}^{p-1} \psi_{i}^{\prime} \Delta z_{t-i}+\omega^{\prime} \Delta x_{t}+\theta w_{t}+u_{t}
$$

En küçük kareler yöntemi ile tahmin edilen bu denklemde $c_{0}$ otonom parametre, $t$ trend değiş̧keni, $\pi_{y y}$ ve $\pi_{y x . x}$ uzun dönem çarpanları, $w_{t}$ tam bağımsız değişkenler vektörü, $u_{t}$ otokorelasyonsuz hata terimidir.

Değişkenler arasında eşbütünleşme ilişkisinin olmadığı şeklinde kurulan temel hipotez ile alternatif hipotez aşağıdaki gibi gösterilebilir:

$$
\begin{aligned}
& H_{0}: \pi_{y y}=0, \pi_{y x . x}=0^{\prime}, \\
& H_{1}: \pi_{y y} \neq 0, \pi_{y x . x} \neq 0^{\prime} \quad \text { veya } \pi_{y y} \neq 0, \pi_{y x . x}=0^{\prime} \quad \text { veya } \pi_{y y}=0, \pi_{y x . x} \neq 0^{\prime}
\end{aligned}
$$

Hesaplanan test istatistiğinin değeri üst kritik değerin üzerinde olduğunda değişkenler arasında eşbütünleşme ilişkisinin olduğu sonucuna varılırken, istatistiğin alt kritik değerden küçük olması durumunda değişkenler arasında eşbütünleşme ilişkisi olmadığına karar verilir. Hesaplanan test istatistiğinin alt ve üst kritik değerlerin arasında olması durumunda ise değişkenlerin durağanlık özelliklerinin incelenmesi gerekmektedir.

Sınır testinde kullanılan model ile değişkenler arasındaki kısa ve uzun dönem esnekliklerini de hesaplamak mümkündür. Kısa dönem esneklikleri; doğrusal regresyon modellerinde kullanılan klasik esneklik hesaplama yöntemiyle hesaplanabilirken, uzun dönem esneklikleri ise Pesaran vd. (1999)'`n önerdiği şekilde, bağımsız değişkenlerin 1 gecikmeli değerlerinin katsayısının bağımlı değişkenin 1 gecikmesine ait katsayıya bölünüp negatif işaretle çarpılması ile hesaplanabilmektedir.

\section{Veri ve Değişkenler}

D1ş ticaret dengesinin temel belirleyicilerini incelediğimiz bu çalışmada veriler Kırgızistan Cumhuriyeti Milli İstatistik Komitesi ve Merkez Bankasından temin edilmiştir. Veri seti 2000.01-2013.11 dönemine ait aylık verilerden oluşmaktadır. Ampirik analize geçmeden önce veriler doğal logaritmik forma çevrilmiştir.

Çalışmada kullandığımız model aşağıdaki gibi gösterilebilmektedir: 


$$
\begin{aligned}
& \Delta L T B_{t}=\alpha_{0}+\sum_{i=1}^{n} \alpha_{1 i} \Delta L T B_{t-i}+\sum_{i=0}^{n} \alpha_{2 i}{ }_{L L G D P S} A_{t-i}+\sum_{i=0}^{n} \alpha_{3 i}{ }_{\Delta L R E E R_{t-i}}+ \\
& +\sum_{i=0}^{n} \alpha_{4 i} \Delta L M 2_{t-i}+\alpha_{5}{ }^{L T B}{ }_{t-1}+\alpha_{6} \text { LGDPSA }_{t-1}+\alpha_{7} \text { LREER }_{t-1}+\alpha_{8} L M 2_{t-1}+v_{t}
\end{aligned}
$$

Modeldeki TB, GDP, REER ve M2 sırasıyla ticaret dengesini (ihracatın ithalata oranı şeklinde), yurtiçi geliri, reel döviz kurunu (ağırlıklandırılmış reel efektif döviz kuru) ve parasal büyüklüğü (para arzı) ifade etmektedir. Verilerin aylık olması nedeniyle mevsimsellik etkisi araştırılmıştır. Yurtiçi gelir serisinde mevsimsel etkinin olması nedeniyle düzeltmeye tabi tutulmuştur.

\section{Bulgular}

Değişkenlerin I(2) ikinci dereceden bütünlenen olup olmadıkları Genişletilmiş Dickey-Fuller (ADF) testi ile incelenmiştir.

Tablo: 2

Birim Kök Testi Sonuçları

\begin{tabular}{llll}
\hline & ADF & & \\
\hline Değişkenler & Düzey & İlk farklar & Sonuç \\
\hline LTB & & & I $(0)$ \\
LGDPSA & $-7.975538^{* * * *}$ & & I $(0)$ \\
LREER & $-5.359637^{* * *}$ & $-11.31580^{* * * *}$ & I $(1)$ \\
LM2 & -2.092326 & $-15.37432^{* * *}$ & I $(1)$ \\
\hline
\end{tabular}

Not: ***\%1 hata payına göre anlaml.

Tablo: 2'deki sonuçlara göre serilerin I(2) ikinci dereceden bütünlenen olmadıkları görülmüştür. Sınır testinde seçilen gecikme uzunluğu 2'dir. Bu gecikme uzunluğunda otokorelasyona rastlanmamıştır. Bu gecikme uzunluğuna göre yapılan sınır testi Tablo: 3 'te özetlenmiştir.

Tablo: 3

\section{Sınır Testi Sonuçları}

\begin{tabular}{ccccc}
\hline \multirow{2}{*}{$\mathrm{\kappa}$} & \multirow{2}{*}{ F test istatistĭ̆i } & \multicolumn{2}{c}{$\% 5$ Kritik değerler } & \multirow{2}{*}{ Olasılık değeri } \\
\cline { 3 - 4 } & & Alt sınır I $(0)$ & Üst sınır I $(1)$ & \\
\hline 3 & 9.007900 & 3.23 & 4.35 & 0.00000 \\
\hline
\end{tabular}


Hesaplanan F değeri 9.007 Pesaran vd. (2001) kritik değerleri ile karşılaştırılmıştır. 0,05 hata payına göre $\mathrm{F}$ test istatistiği değeri üst sınırdan büyüktür. $\mathrm{Bu}$ durumda seriler eşbütünleşen değildir temel hipotezi reddedilmiştir. Bu sonuca göre ticaret dengesi ile (para arzı, yurtiçi gelir ve reel döviz kuru) arasında uzun dönemli bir ilişkinin olduğu görülmüşsür. Denklemde yer alan açıklayıcı değişken sayısı tabloda k değeri olarak gösterilmiştir. Tahmin edilen ARDL modeli sonuçları Tablo: 4'te verilmiştir.

Tablo: 4

ARDL Modeli Tahminleri

\begin{tabular}{|c|c|c|c|c|}
\hline Değişkenler & Katsayılar & Standart Hatalar & t-değerleri & Olasılik \\
\hline Sabit & -0.636927 & 1.442105 & -0.441665 & 0.6594 \\
\hline DLTB $_{\mathrm{t}-1}$ & -0.073020 & 0.095873 & -0.761629 & 0.4475 \\
\hline $\operatorname{DLTB}_{\mathrm{t}-2}$ & 0.011865 & 0.080475 & 0.147441 & 0.8830 \\
\hline DLREER $_{\mathrm{t}}$ & 0.257100 & 0.760820 & 0.337925 & 0.7359 \\
\hline DL REER $_{\mathrm{t}-1}$ & 0.180932 & 0.767619 & 0.235705 & 0.8140 \\
\hline DLREER $_{\mathrm{t}-2}$ & 0.426240 & 0.765645 & 0.556707 & 0.5786 \\
\hline DLGDPSA & 0.824678 & 0.236448 & 3.487782 & 0.0006 \\
\hline DLGDPSA $_{\mathrm{t}-1}$ & 0.798125 & 0.259460 & 3.076102 & 0.0025 \\
\hline DLGDPSA $_{\mathrm{t}-2}$ & 0.140532 & 0.249181 & 0.563973 & 0.5736 \\
\hline DLM2 & 0.076047 & 0.483176 & 0.157391 & 0.8752 \\
\hline $\mathrm{DLM} 22_{\mathrm{t}-1}$ & 0.398942 & 0.499060 & 0.799386 & 0.4253 \\
\hline $\mathrm{DLM} 2_{\mathrm{t}-2}$ & 0.449665 & 0.492190 & 0.913602 & 0.3624 \\
\hline $\mathrm{LTB}_{\mathrm{t}-1}$ & -0.612161 & 0.102360 & -5.980490 & 0.0000 \\
\hline LREDK $_{\mathrm{t}-1}$ & 0.669183 & 0.272684 & 2.454064 & 0.0153 \\
\hline LGDPSA $_{\mathrm{t}-1}$ & 0.115554 & 0.163670 & 0.706018 & 0.4813 \\
\hline $\mathrm{LM} 2_{\mathrm{t}-1}$ & -0.315502 & 0.111410 & -2.831889 & 0.0053 \\
\hline
\end{tabular}

Modelde değişen varyans olup olmadığı ARCH testi ile incelenmiştir. Test istatistiği değeri 0.177066 (olasılık değeri 0.674468) olarak hesaplanmıştır. Bu sonuçlara göre sabit varyans varsayımı $\% 5$ hata payına göre reddedilememiştir. Modelin artıklarında otokorelasyonun olup olmaması Breusch-Godfrey otokorelasyon testi ile araştırılmıştır. Test istatistiği değeri 0.017939 (olasılık değeri 0.982223) olarak elde edilmiştir. Sonuçlara göre model otokorelasyon problemi içermiyor. Ramsey testi ile regresyonda model kurma hatasının olup olmadığı araştırılmıştır. Test istatistiği değeri 2.382328 (olasılık değeri 0.071888) olarak elde edilmiştir. Sonuçlara göre modelde tanımlama hatası yoktur. Başka bir deyişle ele aldığımız ARDL modeli tüm standart tanımlayıcı testlerden geçmiştir.

Modelde yapısal değişikliği incelemek amacıyla Brown vd. (1975) tarafindan ortaya atılan ardışık artıklarla hesaplanan CUSUMQ testi yapılmıştır. Testin sonuçları Şekil 1 'de verilmiştir. Sonuçlara göre modelin artıkları sınır içinde kalmıştır yani parametreler kararlıdır. 
Şekil: 1

CUSUMQ Testi

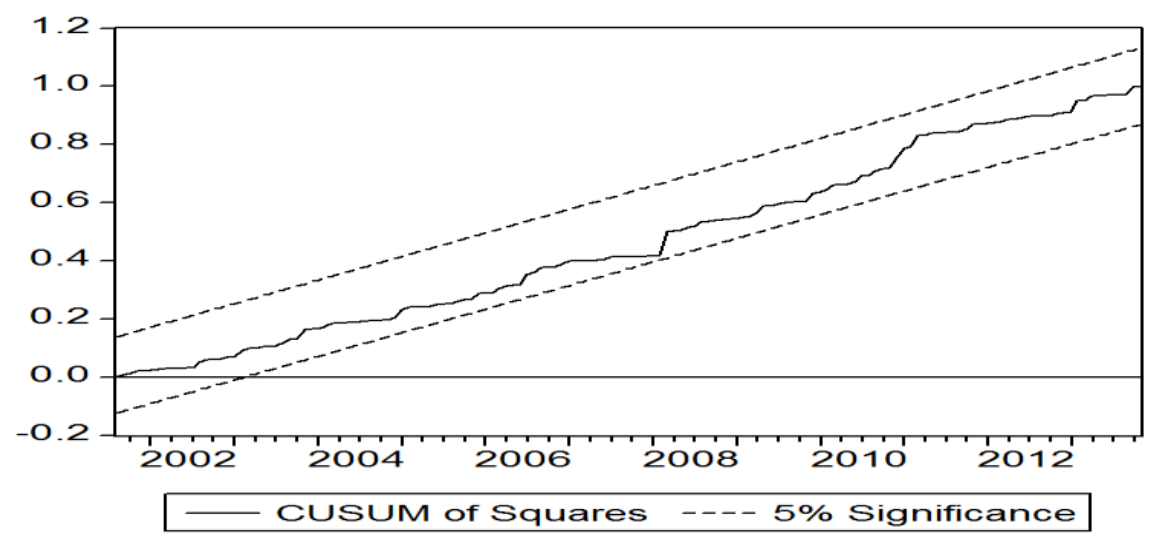

Elde edilen uzun dönem ilişkisinin ardından kullanılan modelden yararlanılarak hesaplanan kısa dönem ve uzun dönem esneklikleri Tablo: 5’te sunulmuştur.

Tablo: 5

\section{Uzun ve Kısa Dönem Esneklikler}

\begin{tabular}{llllll}
\hline Uzun dönem & & \multicolumn{5}{c}{ K1sa dönem } \\
\hline LGDPSA & LREER & LM2 & LGDPSA & LREER & LM2 \\
\hline 0.188764 & $1.093149^{* *}$ & $-0.515390^{* * *}$ & -0.331357 & $0.053450^{* *}$ & $1.381098^{* *}$ \\
$(0.266445)$ & $(0.419841)$ & $(0.162423)$ & $(0.469332)$ & $(0.021780)$ & $(0.487695)$ \\
\hline
\end{tabular}

Notlar: Parantez içinde standart hatalar verilmiştir.

**\%5 düzeyinde anlamlılıklarını gösterir.

Tablo: 5'teki sonuçlara göre reel döviz kuru (LREER) ve para arzı (LM2) serilerinin kısa ve uzun dönem esnekliklerinin istatistiksel olarak anlamlı oldukları, yurtiçi gelir (LGDPSA) değişkeninin ise istatistiksel olarak anlamlı olmadığı görülmektedir.

Uzun dönemde para arzı ile ticaret dengesi arasında negatif yönde bir ilişkinin varlığı görülmektedir. Para arzındaki (LM2) \%1'lik düşüş ticaret dengesini \%0,51 oranında iyileştirir. Kısa dönemde ise para arzının ticaret dengesi üzerindeki etkisi pozitif yöndedir. 
Modelde reel döviz kuru (LREER) katsayısının birden büyük ve anlamlı olması Kırgızistan'da uzun dönemde Marshall-Lerner koşulunun geçerli olduğunu ve böylece döviz kurunun ticaret dengesi üzerinde anlamlı bir etkiye sahip olduğunu göstermektedir. Döviz kurundaki \%1'lik artış ticaret dengesini \%1,09 oranında iyileştirir. Kısa dönemde de döviz kuru katsayısının pozitif ve anlamlı olması J-eğrisi etkisinin gözlemlenmediğine işaret etmektedir.

Kısa dönemde J-eğrisi etkisinin geçerliliği etki-tepki fonksiyonuyla da incelenmiştir. VAR (2) modelinin etki-tepki fonksiyonu Şekil: 2'de verilmiştir. Bu gecikme uzunluğunda otokorelasyona rastlanmamıştır. Sonuçlara göre döviz kuru varyansındaki bir birimlik şoka karşı ticaret dengesinin ilk tepkisi pozitif yöndedir. Böylece J-eğrisi hipotezinin ülkede geçerli olmadığı kanısına varılabilir.

Şekil: 2

\section{Reel Döviz Kurundaki Şoka Karşı Ticaret Dengesinin Gösterdiği Tepki}

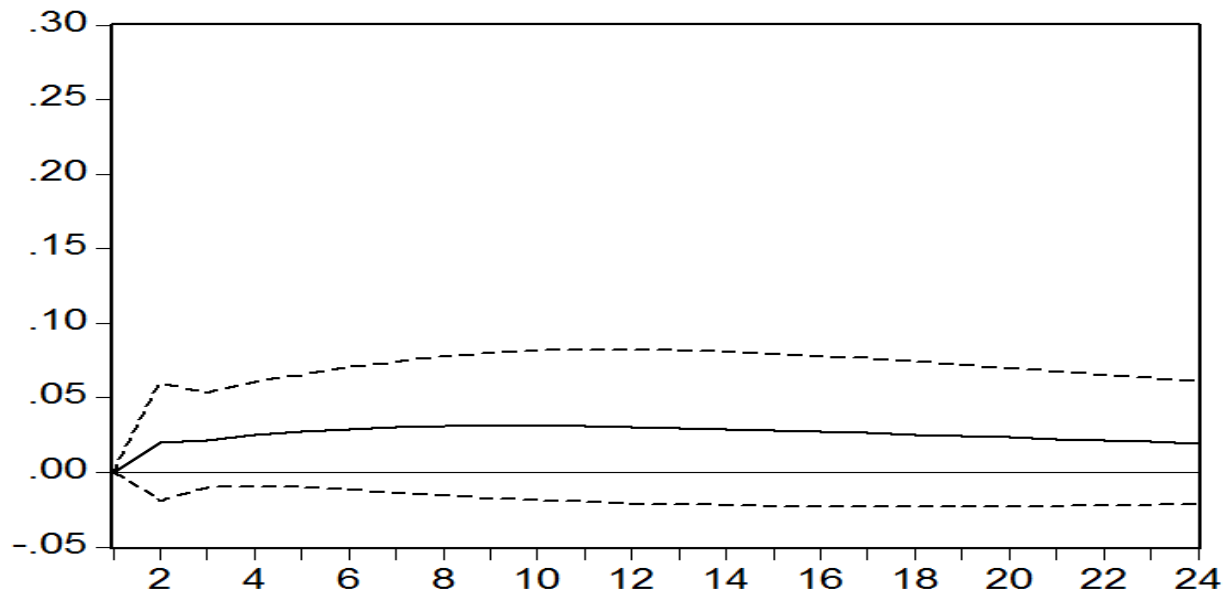

Bu bağlamda Kırgızistan'da reel döviz kuru ve parasal büyüklüklerin ticaret dengesi üzerinde anlamlı bir etkisinin olduğu söylenebilir. Diğer bir deyişle elastikiyet ve parasalcı yaklaşımları destekleyen bulgular elde edilmiştir. Milani (1989: 71) elastikiyet ve parasalcı yaklaşımların biri birini tamamlayıcı nitelikte olduğunu vurgulamıştır. Çalışmadan elde ettiğimiz bulgular da bunlara uygunluk göstermektedir. 


\section{Sonuç}

2000-2013 dönemine ait aylık verilerin kullanıldığg bu çalışmada Kırgızistan'ın dış ticaret dengesinin temel belirleyicileri incelenmiştir. Birim kök testi sonuçlarına göre, dış ticaret açığı ve yurtiçi gelir değişkenleri düzey değerleri ile reel döviz kuru ve para arzı değişkenleri ise ilk farkları alındığında durağan hale gelmektedir. Değişkenlerin farklı derecede durağan olmaları ve ele alınan gözlem sayısının sınırlı olması nedeniyle söz konusu değişkenler arasındaki ilişkiler, Pesaran vd. tarafından geliştirilmiş olan sınır testi yaklaşımına dayanan ARDL modeli ile incelenmiştir.

Sınır testine dayanan ARDL modeli sonuçları ticaret dengesi ile açıklayıcı değişkenlerin uzun dönemde birlikte hareket ettiklerini göstermiştir. Yani uzun dönemde ticaret dengesi, yurtiçi gelir, reel döviz kuru ve para arzı değişkenlerinin arasında eşbütünleşme ilişkisinin varlığına dair bulgular elde edilmiştir. Bulgulara göre, reel döviz kurundaki ve para arzındaki değişmeler, dış ticaret dengesi için önemli bir belirleyicilerdir. Başka bir ifadeyle reel döviz kuru \% 1 oranında arttı̆̆ında ticaret dengesinde \%1,09 oranında ve para arzı $\% 1$ oranında azaldığında ise ticaret dengesinde $\% 0,51$ oranında iyileşme meydana gelecektir. Modelde ayrıca reel döviz kuru katsayısı ve para arzı katsayılarının istatistiksel olarak anlamlı ve işaretlerin de beklenilen yönde olması, modelin parasalcı ve elastikiyet yaklaşımlarına uygun olduğunu göstermiştir. Bulgular, uzun dönemde MarshallLerner koşulunun geçerli olduğunu, kısa dönemde ise J-eğrisi hipotezinin ülkede geçerli olmadığını göstermektedir.

Bu bağlamda, elde edilen tahmin sonuçları bir bütün olarak değerlendirildiğinde, Kırgızistan'da dış açıkları gidermede para ve kur politikalarının etkili olabileceğine işaret etmektedir. Diğer bir deyişle Kırgızistan için yapılan analizler para ve kur politikaları aracılığıyla dış açıkların giderilmesinin olanaklı olduğunu göstermektedir. Yani döviz kurları ile ticaret dengesi arasında istikrarlı uzun dönemli ilişkinin varlığı, devalüasyon ile ülke ekonomisinin rekabet gücü artırılıp dış ticaret açığı sorununun çözülebileceğini ima etmektedir. Ancak unutulmamalıdır ki, son yıllarda ihracat, önemli ölçüde ithal girdilere bağımlı hale gelmiştir. Dolayısıyla döviz kurunu yükseltmeye yönelik olarak uygulanacak politikaların ülkede üretimi ve ihracatı olumsuz yönde etkileyebileceği göz önünde bulundurulmalıdır. Döviz kurunun arttırılması, ara malı ithalat fiyatını yükselterek, maliyet enflasyonuna yol açabilecektir. Bu nedenle uygulanacak döviz kuru politikalarında, ara malı ile nihai tüketim malları ithalatı ayrıştırılmalıdır. Para politikasına gelince, para arzının uzun dönemde diş dengesizlikleri giderici yönde hareket ettiği görülmüştür. Parasalcı yaklaşıma göre ticaret dengesindeki dengesizlikler para arzı ve para talebiyle açıklanabilmektedir. Yani ülke içinde para talebi para arzını aşarsa bu talep yurtdışından giren para akımıyla karşılanacaktır. $\mathrm{Bu}$ durumda ticaret dengesi iyileşecektir. Yani sıkı para politikası 
uygulamalarının dış açıkların kapatılmasında etkin bir politika aracı olarak kullanılabileceği söylenebilir.

Sonuç olarak çalışmadan elde edilen ampirik bulgulara göre Kırgızistan'da dış açıkların azaltılması için para ve kur politikalarının birlikte ve uyumlu olarak kullanılmasının gereklilik arz ettiği kanısına varılabilir.

\section{Kaynakça}

Alexander, S. (1952), "Effects of a Devaluation on a Trade Balance", International Monetary Fund, Staff Papers, 2(2), 263-278.

Alexander, S. (1959), "The Effects of Devaluation: A simplified Synthesis of Elasticities and Absorption Approaches", American Economic Review, XLIX (2), 22-42.

Bahmani-Oskooee, M. \& T.J. Brooks (1999), "Bilateral J-Curve between US and Her Trading Partners", Weltwirtschaftliches Archiv 135(1), 156-165.

Bickerdike, C.F. (1920), “The Instability of Foreign Exchanges”, The Economic Journal, 30(117), $118-122$

Brown, R.L. \& J. Durbin \& J.M. Evans (1975), “Techniques for Testing the Constancy of Regression Relationships over Time", Journal of the Royal Statistical Society, Series B 37(2), 149163.

Duasa, J. (2007), "Determinants of Malaysian Trade Balance: An ARDL Bound Testing Approach", Journal of Economic Cooperation, 28(3), 21-40.

Gomes, F.A.R. \& L.S. Paz (2005), "Can real exchange rate devaluation improve the trade balance? The 1990-1998 Brazilian case", Applied Economics Letters, 12(9): 525-528.

Harberger, A.C. (1950), "Currency Depreciation, Income and the Balance of Trade", The Journal of Political Economy, 58 (1), 47-60.

Hooy, Chee-Wooi \& Tze-Haw Chan (2008), "Examining Exchange Rates Exposure: J-Curve and the Marshall-Lerner Condition for High Frequency Trade Series between China and Malaysia", MPRA Paper, 10916, University Library of Munich, Germany, 1-10.

İrhan, H.B. \& N.D. Alacahan \& L. Korap (2011), “An Empirical Model for the Turkish Trade Balance: New Evidence from ARDL Bounds Testing Analyses”, Ekonometri ve İstatistik $14,38-61$.

Johnson, H.G. (1972), "The Monetary Approach to Balance-of-Payments Theory", The Journal of Financial and Quantitative Analysis, 7(2), 1555-1572.

Johnson, H.G. (1977), "The Monetary Approach to Balance of Payments Theory and Policy: Explanation and Policy Implications", Economica, 44(175), 217-229.

Kim, A. (2009), “An Empirical Analysis of Korea's Trade Imbalances with the US and Japan”, Journal of the Asia Pacific Economy, 14(3), 211-226.

Lal, A.K. \& T.C. Lowinger (2002), "Nominal Effective Exchange Rate and Trade Balance Adjustment in South Asia Countries", Journal of Asian Economics, 13, 371-383. 
Liew, K.S. \& K.P. Lim \& H. Hussain (2003), "Exchange Rates and Trade Balance Relationship: The Experience of ASEAN Countries", International Trade, 0307003, Econ WPA.

Magee, S.P. (1973), “Currency Contracts, Pass Through and Devaluation”, Brooking Papers on Economic Activitiy, 1, 303-25.

Matesanz, D. \& G. Fugarolas (2009), "Exchange Rate Policy and Trade Balance: a Cointegration Analysis of the Argentine Experience since 1962", Applied Economics, 41, 2571-2582.

Metzler, L. (1948), A Survey of Contemporary Economics, Vol. I (Homewood, IL: Richard D. Irwin).

Meade, J.E. (1951), The Balance of Payments, Oxford: Oxford University Press.

Milani, H. (1989), "Devaluation and the Balance of Trade: A Synthesis of Monetary and Elasticity Approaches", International Economic Journal, 3(3):71.

Muhammad, S.D. (2010), "Determinant of Balance of Trade: Case Study of Pakistan”, European Journal of Scientific Research, 41(1), 13-20.

Mundell, R.A. (1968), International Economics, New York Macmillan.

Narayan, P.K. \& S. Narayan (2004), “The J-Curve: Evidence from Fiji”, International Review of Applied Economics, 18(3), 369-380.

Narayan, P.K. (2004), "New Zealand's Trade Balance Evidence of the J-Curve and Granger Causality", Applied Economics Letters, 11, 351-354.

Ng, Y.L. \& W.M. Har \& G.M. Tan (2008), "Real Exchange Rate and Trade Balance Relationship: An Empirical Study on Malaysia", International Journal of Business and Management, 3(8), 130-137.

Onafowora, O. (2003), "Exchange Rate and Trade Balance in East Asia: Is There a J-Curve?", Economics Bulletin, 5(18), 1-13.

Ono, M. \& S.J. Baak (2014), "Revisiting the J-Curve for Japan”, Modern Economy, 5, 32-47.

Pesaran, M.H. \& Y. Shin (1999), “An Autoregressive Distributed Lag Modelling Approach to Cointegration Analysis in Econometrics and Economic Theory in the 20th Century", The Ragnar Frisch Centennial Symposium, ed. S. Strom, Cambridge: Cambridge University Press.

Pesaran, M.H. \& Y. Shin \& R.J. Smith (2001), "Bounds Testing Approaches to the Analysis of Level Relationships", Journal of Applied Econometrics, 16, 289-326.

Polak, J.J. (1957), “Monetary Analysis on Income Formation and Payments Problems", International Monetary Fund Staff Papers, 6, 1-50.

Ray, S. (2012), “An Analysis of Determinants of Balance of Trade in India”, Research Journal of Finance and Accounting, 3(1), 73-83.

Rincon, H. (1998), "Testing the Short and Long Run Exchange Rate Effects on Trade Balance: The Case of Colombia", Submitted Ph.D. Thesis, University of Illinois, Urbana-Champaign.

Robinson, J. (1947), “The Pure Theory of International Trade”, The Review of Economic Studies, 14(2), 98-112.

Singh, T. (2002), "India's trade balance: the role of income and exchange rates", Journal of Policy Modeling, 24, 437-452. 
Sun, C.H. \& Y.B. Chiu (2010), “Taiwan's Trade Imbalance and Exchange Rate Revisited”, Applied Economics, 42, 917-922.

Shirvani, H. \& B. Wilbratte (1997), "The Relationship between the Real Exchange Rate and the Trade Balance: An Empirical Reassessment”, International Economic Journal, 11(1), 3951 .

Weixian, W. (1999), “An Empirical Study of the Foreign Trade Balance in China”, Applied Economics Letters, 6(8), 485-490.

Wilson, P. \& K.C. Tat (2001), "Exchange Rates and the Trade Balance: the Case of Singapore 1970 to 1996", Journal of Asian Economics, 12(1), 47-63. 
Pirimbaev, J. \& Z. Oskonbaeva (2015), “Kırgızistan Dış Ticaret

Dengesinin Belirleyicileri”, Sosyoekonomi, Vol. 23(25), 79-91. 